\title{
Production and Evaluation of Antimicrobial Microcapsules with Essential Oils Using Complex Coacervation
}

\author{
A. López ${ }^{1}$, M. J. Lis ${ }^{1}$ (), F. Maesta Bezerra ${ }^{2}$, M. Vilaseca ${ }^{1}$, B. Vallés ${ }^{1}$, R. Prieto ${ }^{1}{ }^{,}$M. Simó ${ }^{1}$ \\ ${ }^{1}$ INTEXTER-UPC, Barcelona, Spain; ${ }^{2}$ Department of Textile Engineering, Federal Technological University of \\ Paraná, Apucarana, Brasil
}

Correspondence to: M. J. Lis, manuel-jose.lis@upc.edu

Keywords: Microcapsules, Antimicrobial, Biofunctional Textiles

Received: June 11, $2019 \quad$ Accepted: August 16, $2019 \quad$ Published: August 19, 2019

Copyright $\odot 2019$ by author(s) and Scientific Research Publishing Inc.

This work is licensed under the Creative Commons Attribution International License (CC BY 4.0).

http://creativecommons.org/licenses/by/4.0/

\section{(c) (1) Open Access}

\section{ABSTRACT}

Nowadays, the needs and requirements to avoid infections during surgical operations, require to be more imaginative than ever. The one-use textiles substrates that are used in hospitals can be, also, a way to transport the antibacterial effect around the own building. This is the main objective of this work; to use clothes and textiles surfaces as antibacterial systems using natural components. Microencapsulation has shown in several occasions the effectivity to protect and vehiculize active principles that can be used for medical treatments. In this case, essential oils have been used as antimicrobial agent, that when combined with shell polymers based on Chitosan of different molecular weight distribution and Arabic gum, allows them to act against Gram (+) and Gram (-) bacteria. The study of the efficiency of all the samples made gave a high value due to its character similar to hydrogels, while the determination of solids was higher when it was a question of samples made with a low molecular weight. The essential oil used has a very volatile character formed by more than $\mathbf{4 0}$ components and with the help of FT-IR and TGA it has been possible to corroborate that all its components were encapsulated. The impregnation of the different samples to the tissue was successful and allowed the antibacterial study to be carried out, which was carried out in duplicate on each sample and demonstrated that they have bacterial activity.

\section{INTRODUCTION}

When someone gets into a hospital, what is it more dangerous to the patient, his hospital stay or his own income? $[1,2]$. Nowadays, more than $15 \%$ of the people who enter the operating theatre are infected 
by nosocomial diseases [3]. These diseases may affect the patient in many ways depending on his conditions. The main operating theatre contamination is people, but the only means of infection that their skin has is the dressing gown they wear.

In this research we'll try to give a possible solution to this big problem based on a stable material that can be impregnated in a fabric and obtained from microencapsulation, a storage technology which allows to produce the release of an active substance $[4,5]$.

The encapsulation technique is widely used in micro-biomedicine, which allows to apply micro and nano scale principles and techniques to transform inert materials into medical purposes. The nanotechnology, biomedicine and biology integration is expected to go faster into the next decade [6]. Antibiotics were first used more than 90 years ago to fight against infections but, since the microbial polymer than can attack a gene, a microbe or a cellular process was discovered, there have been some and great alternatives to these problems $[7,8]$.

Biological-based polymers arise as a solution to the replacement of the petroleum-based ones, with the aim to reduce dependence on crude petroleum, since it's a limited source [8]. Chitosan is a biopolymer that belongs to the group of polysaccharides, where natural origin and biodegradability plays an important role and conditions its chemical final properties $[9,10]$.

Encapsulation has many applications, so you must know what you want to get to choose the correct one [11-13]. Basically, encapsulation can be defined as the inclusion of an active principle molecule (core) into an ordered structure constituted by polymers (shell). Therefore, to choose the appropriate components of the whole structure, is a challenge for each active principle molecule.

Complex coacervation is one of the most useful methods to encapsulate fragrances, due to the presence of high volatile molecules inside its formulation $[14,15]$. This method is based on the union of two polymers at low temperatures in order to get an electrostatic attraction, setting hydrophobic interactions. In this work, chitosan will be used as one of the polymer, due to its special characteristics, among them: antimicrobial and biodegradable. These properties, depend, strongly on its molecular weight distribution. The other biopolymer used, will be arabic gum, carbohydrate macromolecule that would infere testability to the final microcapsule [11].

An essential oil has been used as an active substance in this research (core), since it's considered a natural medicine for its antibacterial, antiviral, antiparasitic and antioxidant properties due to the presence of a phenolic group in its structure [16].

The main objective of this research is to relate different phenomena such as the microbiology and physics-chemistry using microcapsules as agents to hold essential oils in an immobile system and to be able to impregnate it in a fabric. The physic and chemical properties of the synthetic microparticles were evaluated using different characterization, optical microscopy techniques (OM), infrared Fourier transform spectroscopy (FTIR), zetasizer and UV-VIS molecular spectroscopy techniques. Antibacterial properties of the formed devices with microcapsules were investigated using several microorganisms of gram-positive and gram-negative interest, including Staphylococcus aureus and Escherichia coli.

\section{EXPERIMENTAL PROCEDURE}

\subsection{Materials}

Chitosan (molecular weight between 300,000 - 105,000 Da) from Sigma Aldrich, and gum arabic from Sigma Aldrich were used as shell-forming materials. Lavender used as core agent, Tween 20 (Polysorbate 20) as nonionic surfactant, tannic acid and $0.1 \mathrm{~N}$ acetic acid, used to dissolve Chitosan, were purchased from Sigma Aldrich. Citric acid and monobasic sodium phosphate monohydrate(PANREAC, Spain) were used in the grafting reaction. A textile substrate, standard 100\% cotton (ISO 105-F02, $115 \mathrm{~g} / \mathrm{m}^{2}$ ) was used.

MicroZoom Microscope (Bausch \& Lomb, N.Y., United States) with ProgRes C3 has been used to get pictures of microcapsules. FTIR-8300 (Shimadzu, Japan), UV-2401 (Shimadzu, Japan), Thermogravimetric Analyser 851e (Mettler-Toledo, United States) and Zeta Sizer Nano-ZS (Malvern, UK) were the instruments used for the characterization of microcapsules microstructure. 


\subsection{Microcapsules Production}

The method used for the production of microcapsules is the complex coacervation between gum arabic and Chitosan. A process of 4 different steps has been used, but with modifications such as references [17-20].

The first step is to achieve the dissolution between Chitosan and gum arabic, where each dissolution is prepared separately beforehand. The Chitosan solution was prepared by diluting with $0.1 \mathrm{~N}$ acetic acid and magnetic agitation for 16 hours. Gum arabic is prepared with $2 \%(\mathrm{w} / \mathrm{v})$ using magnetic stirring at elevated temperatures to reach a complete dissolution. The two solutions were mixed to form the shell material and different concentrations of surfactant and essential oil are added as shown in Table 1.

Once the mixture is achieved, it is emulsified for $1 \mathrm{~min}$ at high stirring rate (Ultraturrax T-25, IKA, Germany). Next, the third step necessary to obtain the microcapsules was to lower $\mathrm{pH}$ value to 3 with $\mathrm{N}$ $0.2 \mathrm{HCl}$ solution.

Finally, it is necessary to harden the microcapsules and in order to achieve this, $2 \mathrm{ml}$ of tannic acid is added to the mixture and it is left in agitation for 3 hours.

This same procedure is done with the different molecular weights of the Chitosan as can be seen in Table 2 .

\subsection{Microbiological Test}

Experiments were designed based on the AATCC protocol 147_“Antibacterial Assessment of textile materials" [21].

The main objective of this analysis is to check the bacterial activity of each tissue sample, at static conditions and is useful for to estimate the activity. It is based on the growth of the organism when it comes in close contact with the impregnated sample, keeping the tissue only submitted to the diffusion and transport mechanisms promoted by its own structure.

Table 1. Components of the different samples of microcapsules.

\begin{tabular}{ccc}
\hline Chitosan & Active principle $(\mathrm{g})$ & Tensioactive $(\mathrm{g})$ \\
\hline 1 & 0.2 & - \\
2 & 0.2 & 0.35 \\
3 & 1 & - \\
4 & 1 & 0.6 \\
5 & - & - \\
6 & - & 0.6 \\
\hline
\end{tabular}

Table 2. Characteristics and classification of Chitosan polymers used, as shell component, in experiments.

\begin{tabular}{ccc}
\hline & Molecular weight $(\mathrm{KDa})$ & Clasification \\
\hline Chitosan I & 300 & Medium \\
Chitosan II & 288 & Medium \\
Chitosan III & 150 & Low \\
Chitosan IV & 135 & Low \\
Chitosan V & 105,800 & Low \\
\hline
\end{tabular}


Following the instructions by AATCC $[22,23]$, samples were incubated during 24 hours at $37^{\circ} \mathrm{C}$ to see whether our bacteria are antibacterial or not. The study was carried out for the two types of bacteria, described before, Eschericcia coli and Staphylococcus aureus.

\section{RESULTS AND DISCUSSION}

A total of 33 samples have been prepared, following the procedure described in 2.2. Figure 1 shows some of the emulsions obtained, high molecular weight (Chitosan 2) and low molecular weight (Chitosan $5)$.

\subsection{Optical Microscope}

Once samples have been obtained, it is necessary to check microcapsules geometry and external aspect with an optical microscope.

By analyzing each of the samples, those made with a high molecular weight, more microcapsules could be observed compared to those made with a low molecular weight as can be seen in Figure 2 and Figure 3. For the surfactant used, the complex formed during the process, is more effective for high molecular weight polymer chains than for molecules of Chitosan of lower length, what results coherent with the effect expected. The more is the organic character of polymeric chains, the more stability gets the surfactant-polymer structure complexation (chemical affinity).

This is an important point in this study. The effect of a surfactant in microencapsulation processes has been not, extensively studied, and the final structure of polymer chains, surfactant micelles and the molecular interactions between the essential oil and the surfactant complex formed, influences, strongly to the final size of microcapsules. The presence of surfactant molecules, allows the system to acquire more stability what is translated to a reduction of size, when compared to the samples that had only been made with the essential oil in the nucleus of the microcapsule.

1) High Molecular Weight Chitosan;

2) Low Molecular Weight Chitosan.

\subsection{Efficiency}

Efficiency of the procedure, is calculated according to the formula shown below:

$$
\eta=\frac{C_{0}-C_{f}}{C_{0}}
$$

where: $C_{0}$ is the initial concentration in $\mu \mathrm{m} / \mathrm{ml} ; C_{f}$ is the final concentration in $\mu \mathrm{m} / \mathrm{mL}$.

The initial concentration is considered to be that which has been added to each sample. With the help of UV-vis, different spectra are obtained to make calibration curves and determine the final concentration, by interpolation.
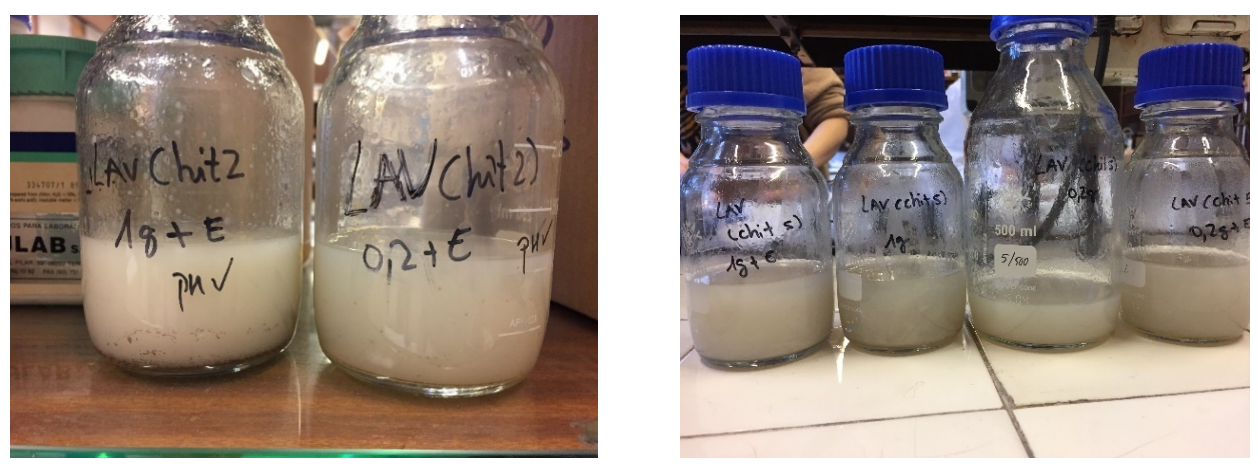

Figure 1. Emulsion samples of high molecular weight (left) and low molecular weight (right). 

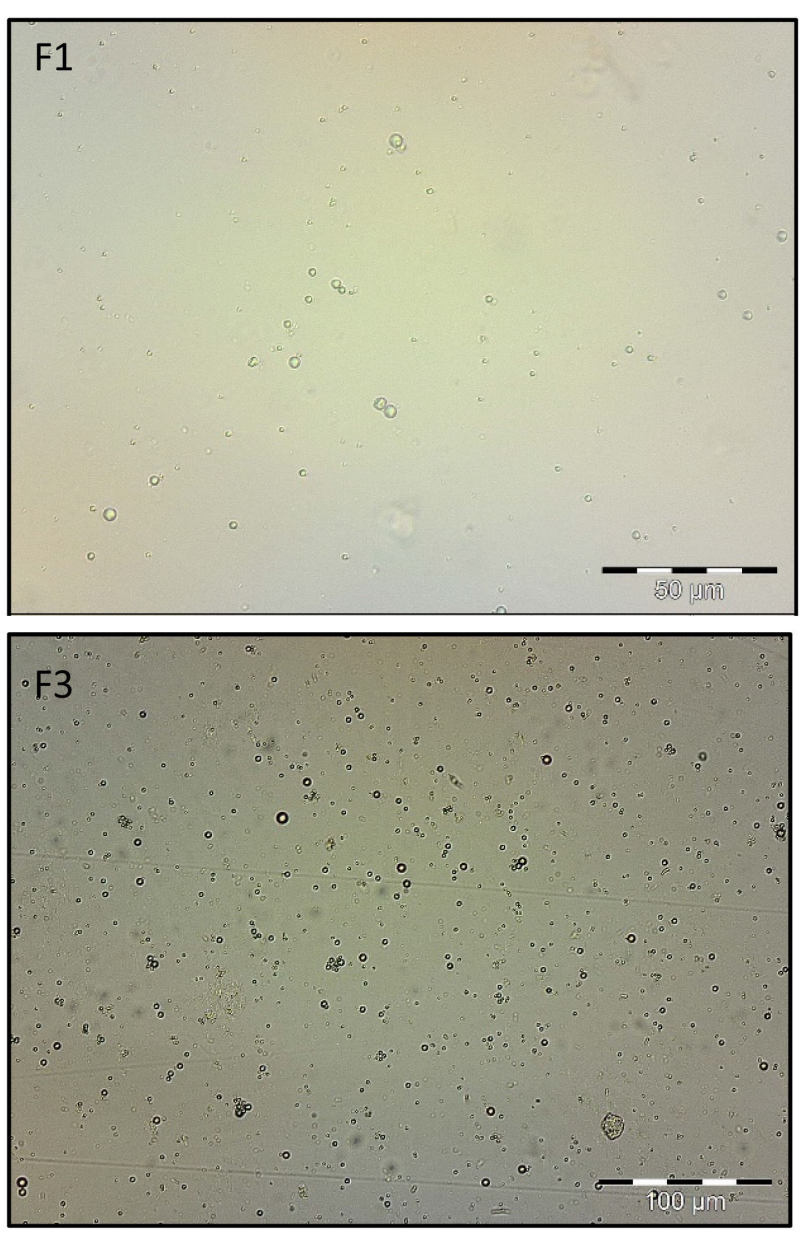

F5

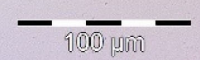

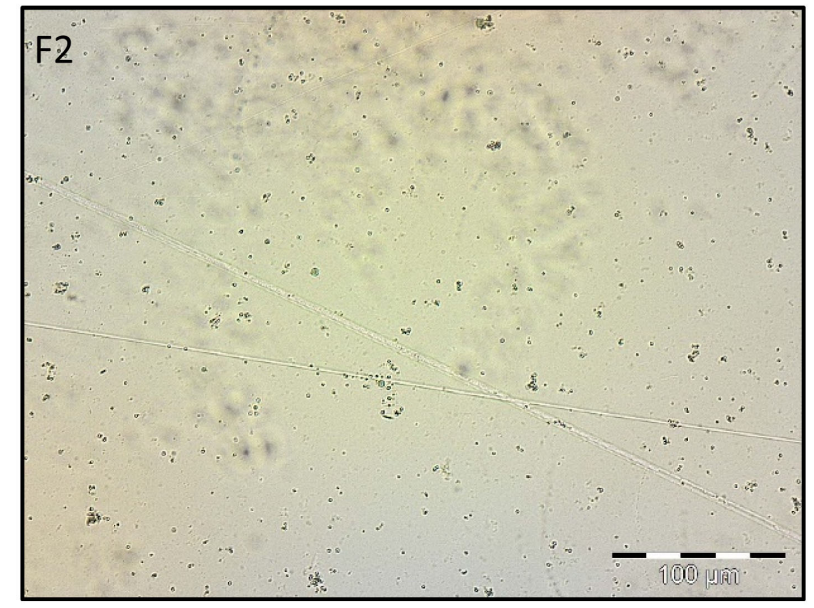

F4

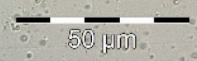

F6

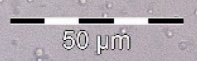

Figure 2. All photos refer to samples made with high molecular weight Chitosan. F1 has $0.2 \mathrm{~g}$ of lavender, F2 has $0.2 \mathrm{~g}$ of lavender with surfactant, F3 has lavender $1 \mathrm{~g}$, F4 has lavender $1 \mathrm{~g}$ with surfactant, F5 has no active ingredient and F6 has only surfactant.

As can be seen in Table 3, all samples have a high encapsulation efficiency due to the formation of hybrid structures that have characteristics of high absorption capability, similar to the expected from hydrogels. The presence of surfactant molecules affects the interface by reducing its tension what helps to facilitate the absorption. 

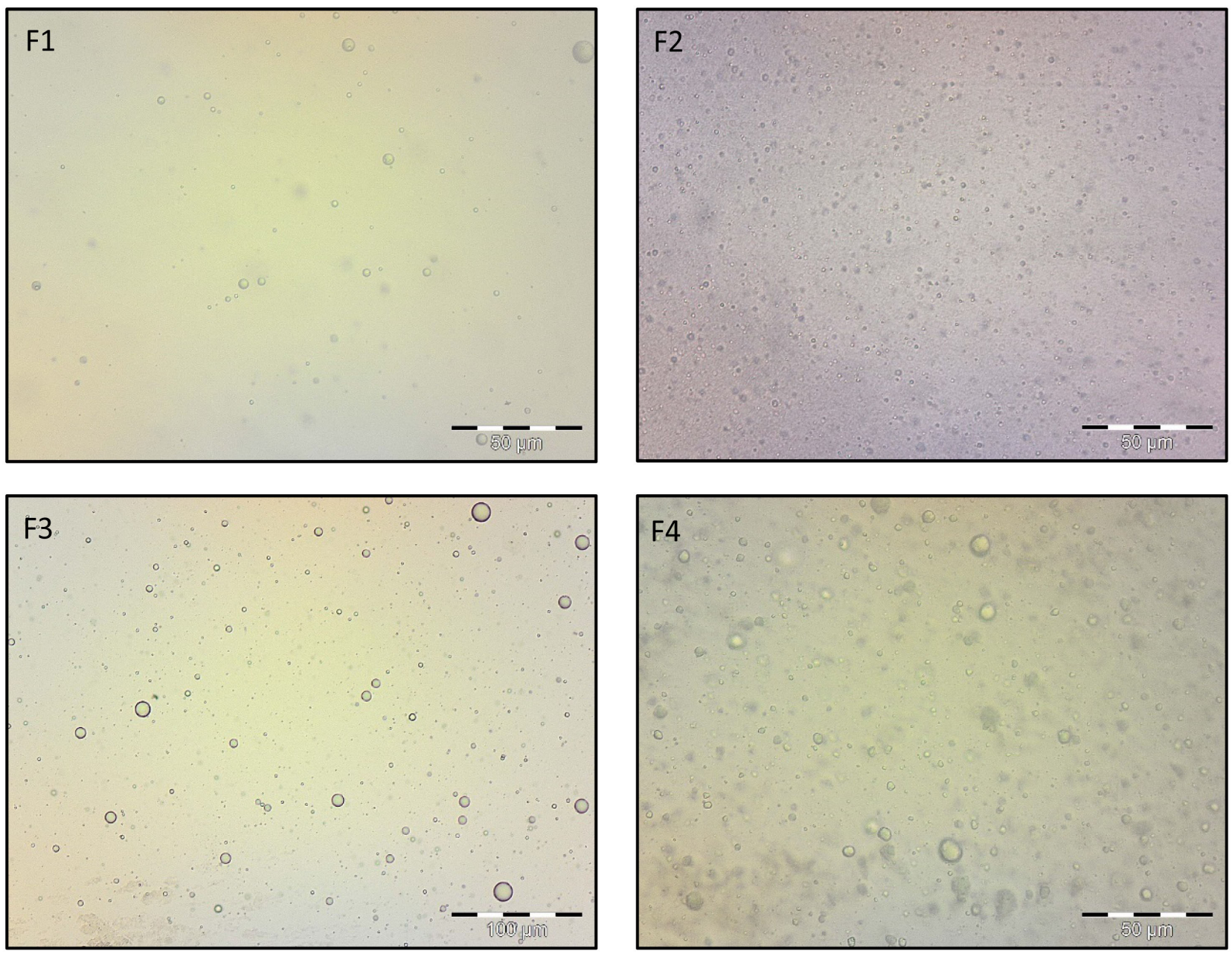

\section{F5}

Figure 3. All photos refer to samples made with low molecular weight Chitosan. F1 has $0.2 \mathrm{~g}$ of lavender, F2 has $0.2 \mathrm{~g}$ of lavender with surfactant, F3 has lavender $1 \mathrm{~g}, \mathrm{~F} 4$ has lavender $1 \mathrm{~g}$ with surfactant, F5 has no active ingredient and F6 has only surfactant.

Following the experimental method of point 2.2, different molecular weights of Chitosan have been used which, as it increases, the encapsulation efficiency decreases. 
Table 3. Comparison of different parameters determined of the high molecular weight Chitosan (1) and that of the low molecular weight (5).

\begin{tabular}{ccccc}
\hline Chitosan & Diameter $(\mathrm{nm})$ & Solid content $(\% \mathrm{w} / \mathrm{w})$ & Efficiency $(\%)$ & \% Weight on the tissue \\
\hline 1 & 951 & 1.057 & 94.18 & 2.96 \\
1 & 310 & 2.128 & 98.34 & 5.23 \\
1 & 1080 & 3.188 & 74.25 & 4.81 \\
1 & 986 & 2.160 & 85.55 & 5.03 \\
5 & 3310 & 12.586 & 91.98 & 7.48 \\
5 & 1590 & 6.573 & 97.65 & 6.16 \\
5 & 985 & 8.711 & 78.73 & 7.13 \\
5 & 598 & 9.755 & 86.40 & 5.83 \\
\hline
\end{tabular}

\subsection{Determination of Solids}

To determine the solid content of microcapsules and following European standard EN 827, $1 \mathrm{~g}$ of the sample checked, must be placed in a watch glass (initial mass), centrifuge to separate the two existing phases, and leave them during 3 hours at $60^{\circ} \mathrm{C}$ (final mass).

$$
\% \text { Weight }=\frac{\text { Final weight }}{\text { Initial weight }} \times 100
$$

This process is repeated twice, for both levels of molecular weight samples. When the samples are made from a low molecular weight in the casing there is more percentage weight. The different values are shown in Table 3 where a comparison is made between the samples made with a high molecular weight of the Chitosan and a low molecular weight.

As expected, centrifugation effects on low molecular weight polymeric chains are more intense than for high molecular chains, due to the presence of the surfactant on the system, that stabilize better the high weight chains due to its more organic chemical character.

\subsection{Percentage by Weight in the Tissue}

The method used for impregnation of the different samples to the tissue is based on the same as in the study of Yang, $\mathrm{Z}$ and Fan, F [24, 25].

A solution is made with each of the samples containing $10 \%(\mathrm{w} / \mathrm{v})$ of the dissolution of the microcapsules, 3\% (w/v) citric acid and 3\% (w/v) monobasic sodium monohydrate (catalyst). With the help of a foulard machine, the samples can be impregnated to cotton from a pressure of 0.5 bar. The drying of the different fabrics is done at room temperature by using the catalyst.

This formula is used to calculate the percentage by weight in the tissue:

$$
\text { \%Tissue weight }=\frac{\text { Tissue weight }(\mathrm{f})-\text { Tissue weight }(0)}{\text { Tissue weight }(0)}
$$

where: Tissue weight $(0)$ is the weight of the fabric before impregnation, in grams. Tissue weight (f) is the weight of the tissue after impregnation in grams.

Experimental results are shown in Table 3. There is a comparison between the samples made with a high molecular weight of Chitosan and samples of low molecular weight. 


\subsection{Particle Size}

The formation of microcapsules is based on to form as table interaction between Chitosan and gum arabic chains in combination with another structure formed by the molecular interactions, previously created, between surfactant and essential oil. Therefore, when microcapsule is formed, there are in equilibrium, between 2 and 3 physical-chemical interactions. Particle size will be affected by the average effect of the joining interactions which will affect, simultaneously, efficiency and molecular weight polymers distribution.

The comparison of the samples made from a high molecular weight and low molecular weight Chitosan can be seen in Figure 4 with Nanosizer ZS.

Chitosan chains with higher molecular weight show much greater interaction than the low molecular weight, therefore, its intensity is stronger and the peak will be larger and narrower. Meanwhile, interactions on the low molecular weight Chitosan chains are weaker and, indeed, they can form more than one aggregate of different cle sizes.

The addition of a surfactant causes the modification of surface tension and, then, interactions would be affected, therefore the particle size is reduced as explained in 3.1.

When a surfactant is added the resultant size distribution is wider, by the formation of 3 different aggregates. The intensity of their interactions is affected, what causes a wide distribution of the particles. Meanwhile, when no surfactant is added, the curve obtained is narrow and shows, only one particle size. Figure 5 shows a comparison of a sample made with a high molecular weight Chitosan and a sample adding surfactant.

When essential oil is added to the microcapsules, two aggregates are formed, as can be seen in Figure 6, which show two peaks. One peak shows the aggregation of the lavender particles (being organic material) and the other shows the aggregation only of Chitosan.

Table 3 shows a compilation of the values of a high molecular weight Chitosan corresponding to number 1 and a low molecular weight corresponding to number 5.

Size Distribution by Intensity

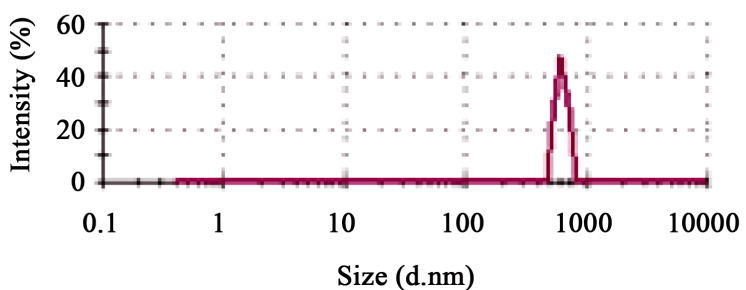

Size Distribution by Intensity

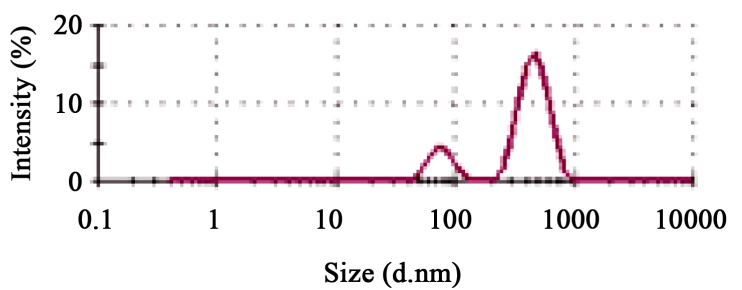

Figure 4. Sample without active ingredient of high molecular weight Chitosan (left) and low molecular weight Chitosan (right).

Size Distribution by Intensity

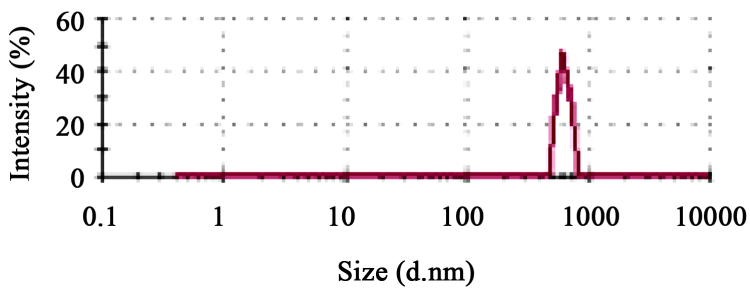

Size Distribution by Intensity

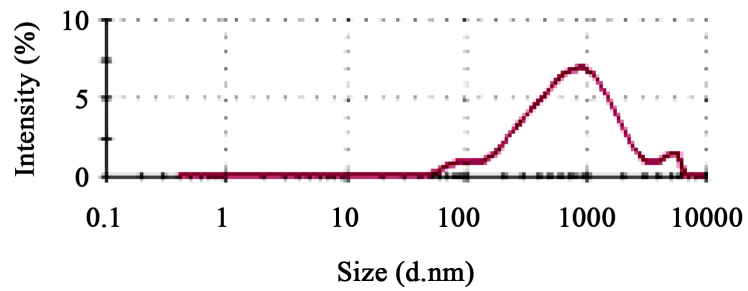

Figure 5. Sample without active ingredient (left) and sample without active ingredient, but with surfactant (right). 
Size Distribution by Intensity

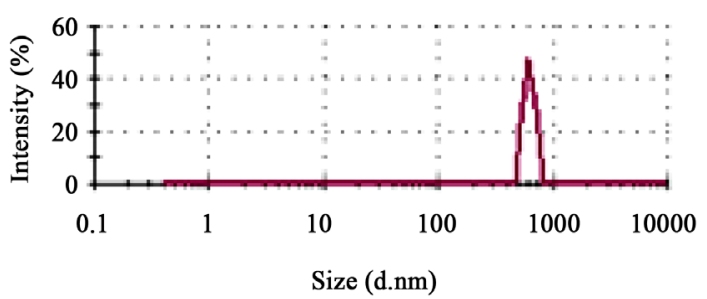

Size Distribution by Intensity

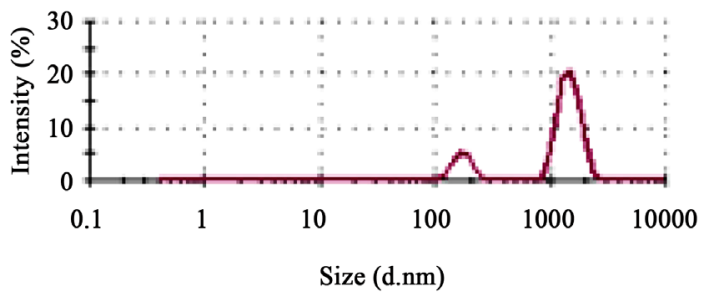

Figure 6. Sample without active ingredient of Chitosan with high molecular weight (left) and Chitosan with $1 \mathrm{~g}$ of lavender (right).

As can be deduced from the results the efficiency is, more or less the same. Between $75 \%$ to $97 \%$ (in average) is obtained. Self-assembly behavior of Chitosan chains, seems to be poorly affected when essential oil is added to the system, what means that, when the active principle is present on the system, it is allocated inside the aggregate structure formed by polymer chains.

The affinity of cotton substrate for the microcapsules is, basically of the same level, what corroborates the fact that is really the character of external polymers on shell, which governs this mechanism.

\subsection{Antibacterial Test}

This test was carried out with the impregnated tissues (80\% pick-up, stainless steel rollers, BENZ, Germany) of the different samples. Staphylococcus aureus (ATCC 19213) and Escherichia coli (ATCC 10536) were used as representatives of gram positive and gram negative bacteria.

Figure 7 shows the results of the antimicrobiological analysis of the samples made with the high molecular weight Chitosan.

Figure 8 shows the results of the different samples made with a low molecular weight Chitosan.

As can be seen from the different images of the antibacterial assay performed with the high molecular weight Chitosan samples was unsuccessful, due to the low weight in the tissue and a much slower diffusion.

Diffusion of the high molecular weight is difficult and slow because the polymer chains are much longer and compact. It was found that as the days went by, the colonies stopped growing in the tissue, while in the plaque they continued to grow. This phenomenon occurs when working in an aqueous medium with agar and the samples containing lavender oil, which is insoluble in it.

In the case of samples made with low molecular weight Chitosan, it was demonstrated that it works and that the tissue has antimicrobial properties. Diffusion is easier in the less ordered structure, water can displace the molecules of the active principle more easily, what is translated to a more antibacterial effectiveness.

All samples were duplicated, as indicates the ATCC Norme applied. Twin samples show the same behavior.

\subsection{FT-IR and TGA}

\subsubsection{Influence of Molecular Weight}

In order to be able to observe the different functional groups of Chitosan molecules, a comparison of the low molecular weight and high molecular weight is shown in Figure 9.

It is observed that in $3414 \mathrm{~cm}^{-1}$ the $\mathrm{OH}$-group, in the $3215 \mathrm{~cm}^{-1}$ the group $-\mathrm{NH}_{2}$. A $2926 \mathrm{~cm}^{-1}$ a section that is part of the link $\mathrm{C}-\mathrm{H}$, a $1664 \mathrm{~cm}^{-1}$ is the vibration of the link $\mathrm{C}=\mathrm{O}$. A $1384 \mathrm{~cm}^{-1}$ Is the group of aromatics $-\mathrm{CH}_{2}$ - and finally we see $1077 \mathrm{~cm}^{-1}$ the link $\mathrm{C}-\mathrm{O}$.

Samples with a high molecular weight imply that their interaction is much higher and that their particles are larger, therefore, when broken, their decomposition will be much stronger than samples containing 

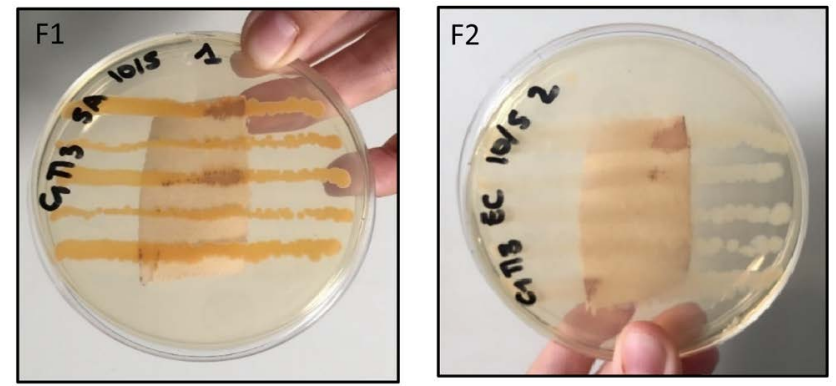

Figure 7. Tissue with sample of Chitosan of high molecular weight. F1 Staphylococcus aureus. F2 Eschericcia coli.
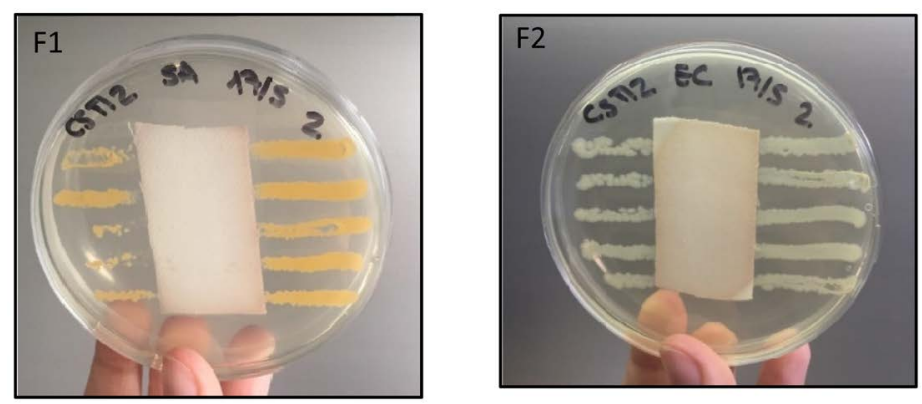

Figure 8. Tissue with a sample of Chitosan of low molecular weight. F1 Staphylococcus aureus. F2 Eschericcia coli.
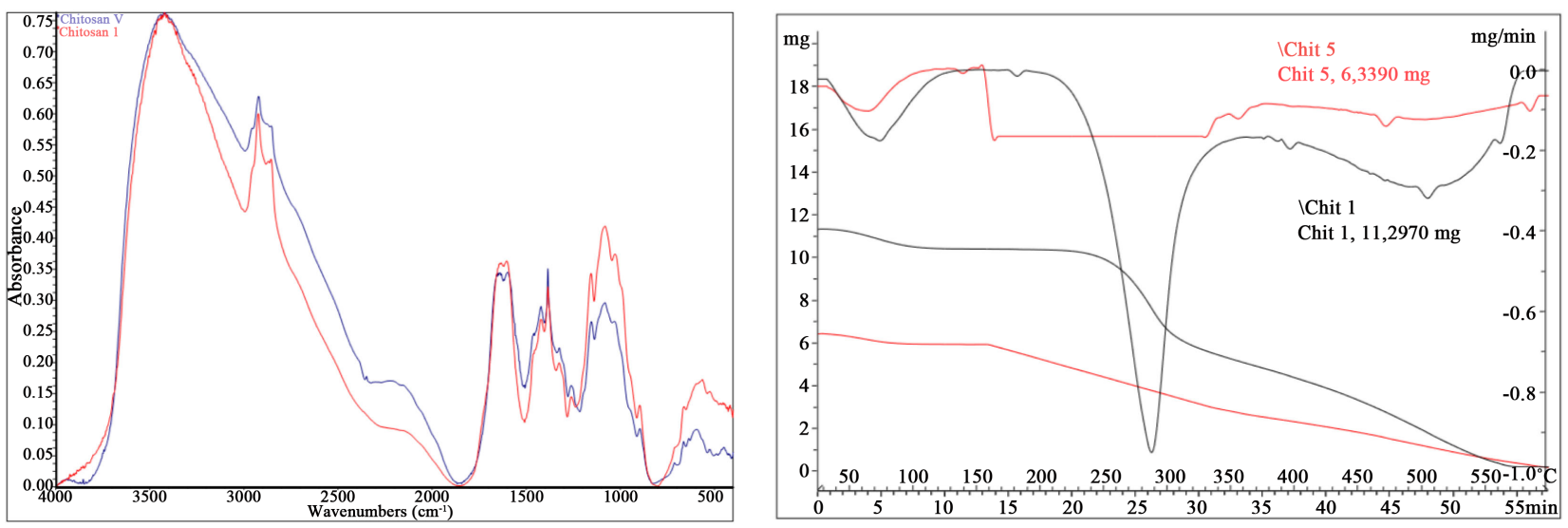

Figure 9. FT-IR comparison of a high molecular weight and a low molecular weight Chitosan (left) and TGA comparison of a high molecular weight and a low molecular weight Chitosan (right).

Chitosan with low molecular weight. In Figure 9, TGA shows only one decomposition peak, and this fact is reflected in each of the thermograms obtained. Another characteristic is that in this case we see that there is only one aggregate, because we only have one component.

\subsubsection{Influence of the Surfactant}

Figure 10 shows the influence of the presence of surfactant on the different samples prepared. Surfactant structure, has no N-H functional group, so it reduces system interaction and intensity in the spectrum of Figure 9 (right). The results were corroborated when comparing with the work of Pantoja-Castro [26]. 
It is observed that the peak begins to round due to the strong -OH bond and the non-existence of the functional group- $\mathrm{NH}_{2}$.

In the surfactant ii is possible to find the group -OH at $3480 \mathrm{~cm}^{-1}$, at $1646 \mathrm{~cm}^{-1}$ the bond $\mathrm{C}-\mathrm{O}$, at 1456 $\mathrm{cm}^{-1}-\mathrm{CH}_{2}$ - and at $1093 \mathrm{~cm}^{-1}$ the signal corresponding to C-O.

In the spectrum of TGA of microcapsules, we can see that there are different breaks, this is because there are different aggregates, either surfactant, cross-linking or gum arabic, something that does not occur in samples that are only prepared with Chitosan. In Figure 10, in the sample only with Chitosan, there is a breakage that is due to its degradation. With the use of surfactant, as explained above, its interaction is reduced, therefore, the rupture and rate of loss of weight with temperature will not be affected as well, as it was only Chitosan.

\subsubsection{Influence of the Active Principle}

When sampling with an essential oil, all components must be encapsulated so that they can have the same properties. In this study lavender is used. It is composed by more than 40 components, and from Figure 11, with the FT-IR spectrum it can be corroborated that all its components could actually, be encapsulated.
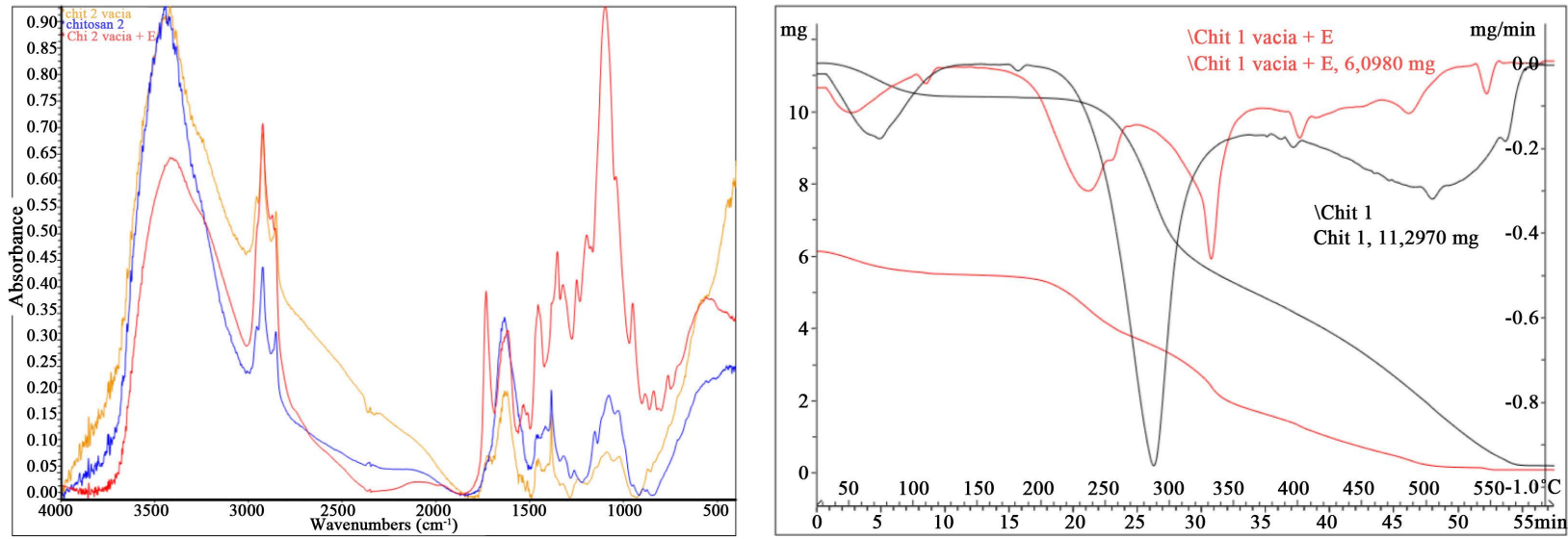

Figure 10. To compare the high molecular weight Chitosan without active ingredient and with surfactant (left) and to compare the TGA of the high molecular weight Chitosan with and without surfactant (right).
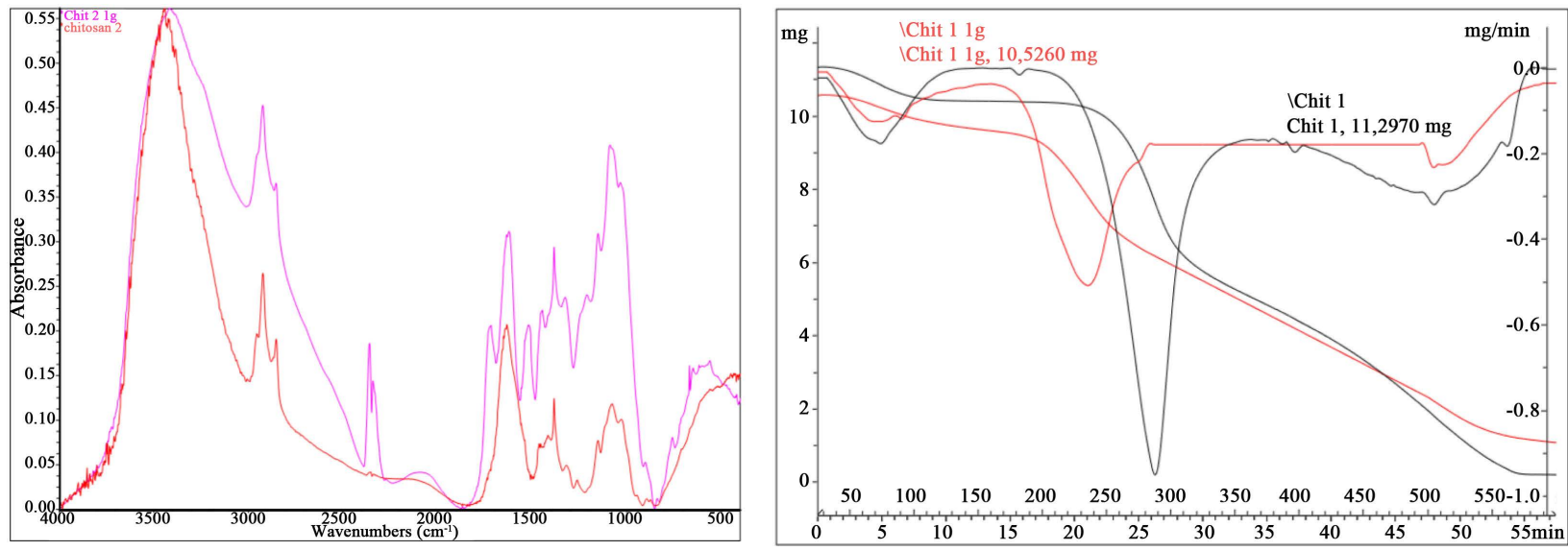

Figure 11. To comparative of Chitosan with lavender in the FT-IR (left) and a comparison of Chitosan with lavender in the TGA (right). 
In the FT-IR spectrum of lavender oil, we can see a signal at $3434 \mathrm{~cm}^{-1}$ which can be attributed to the group $-\mathrm{OH}$, at $1738 \mathrm{~cm}^{-1}$ the double bond of $\mathrm{C}=\mathrm{O}$ that is characteristic of these type of natural essences and that is the responsible of their organoleptic properties.

At $1644 \mathrm{~cm}^{-1}$ we found the signal of $\mathrm{C}=\mathrm{C}$ and at $1412 \mathrm{~cm}^{-1}$ aromatic compounds, that are antibacterial, in nature. The las frequency identified in the spectrum, corresponds at $1109 \mathrm{~cm}^{-1}$ to the bond C-O signal.

From the spectrum of Figure 11 (left) we can observe that microcapsules with lavender, at $1700 \mathrm{~cm}^{-1}$, show a more intense signal, due to the presence of the oil in the structure, as well, as the growing in the aromatics frequency $\left(1400 \mathrm{~cm}^{-1}\right)$ and the signal of $1100 \mathrm{~cm}^{-1}(\mathrm{C}-\mathrm{O})$. The new signal that can be observed at $3000 \mathrm{~cm}^{-1}$ corresponds to tannic acid, used as cross-linker.

As can be seen in Figure 11 (right), TGA/DTGA analysis, allows to compare samples of Chitosan alone and high molecular weight Chitosan with lavender. In the samples where oil is used, its intensity is reduced, and DTGA shows the existence of more than one aggregate. Results also show that there is an earlier degradation of the structure due to the volatile nature of the essential oil, and the less ordered structure that was commented in 3.6.

\section{CONCLUSION}

After completing the set of experiments, it can be affirmed that there has been reached a protocol to obtain microcapsules of fragrance (in this case of lavender) with antibacterial character. Complex coacervation method shows a very good level of efficiency and allows to control the level of hydrolysis combining different molecular weight Chitosan species. Different conclusions have been drawn from the various studies that have been carried out, such as the optical microscope, the calculation of efficiency, the percentage of solids, TGA, FT-IR, particle size and the antimicrobial test. Chitosan has been shown to be a biopolymer with a wide range of applications and is highly dependent on its molecular weight. To begin with, from the different Chitosan of high molecular weight it has been demonstrated that they have a much higher interaction between them; their chains are much longer and are more compact and therefore the diffusion when studying the bacteria is much more difficult. On the other hand, low molecular weight Chitosan has a much weaker interaction between them, but diffusion with the tissue is much faster and more efficient. It has been seen that the Chitosan is not soluble in water at neutral or basic $\mathrm{pH}$, only if it is in acid $\mathrm{pH}$ from that its amine group $\left(-\mathrm{NH}_{2}\right)$ forms the ammonium salt $\left(-\mathrm{NH}_{3}^{+}\right)$. As you can see in the TGA spectra, the high molecular weight Chitosan to have more interaction between them the wall of the microcapsule is much stronger and needs more force to break it, which does not happen in the case of microcapsules with a low molecular weight Chitosan. With FT-IR spectra and efficiency analysis, we realize that lavender is easy to microencapsulate, but being a volatile material, it is difficult to work with both

UV-VIS and aqueous media. With respect to microcapsules samples, the ideal would be to work with a combination of high molecular weight and low molecular weight Chitosan, as their interactions would still be strong, but it would help the diffusion provided by the low molecular weight Chitosan.

\section{CONFLICTS OF INTEREST}

The authors declare no conflicts of interest regarding the publication of this paper.

\section{REFERENCES}

1. Ávila-Figueroa, R., Ramírez-Galván, L., Alpuche-Aranda, C., Arredondo-García, J.L. and Santos-Preciado, J.I. (1986) Infecciones noso-comiales en un hospital pediátrico. Salud Pública de México, 28, 616-622.

http://saludpublica.mx/index.php/spm/article/view/319

2. Hedlund, K.-O., Nordgren, J., Svensson, L., Nybom, R., Hagbom, M. and Wigzell, H. (2015) Ionizing Air Affects Influenza Virus Infectivity and Prevents Airborne-Transmission. Scientific Reports, 5, Article No. 11431. https://doi.org/10.1038/srep11431 
3. Martínez, J.M.A. (2015) Trabajo fin de Grado Infecciones Nosocomiales: Pseudomonas Aeruginosa y su importancia, sus características y su.

4. Lozano Berna, M. (2009) Obtención de microencapsulados funcionales de zumo de opuntia stricta mediante secadso por atomización. Ingeniería Técnica Industrial, Especialidad En Química Insdustrial. Universidad Politécnica de Cartagena, Cartagena, 69.

5. Chinta, S.K. and Pooja, P.W. (2013) Use of Microencapsulation in Textiles. Indian Journal of Engineering, 3, 37-40. http://www.discovery.org.in/ije.htm

6. Bronzino, J.D. (2006) The Biomedical Engineering Handbook, Vol. I: Biomedical Engineering Fundamentals.

7. Álvarez-Paino, M., Muñoz-Bonilla, A. and Fernández-García, M. (2017) Antimicrobial Polymers in the Nano-World. Nanomaterials, 7, 48. https://doi.org/10.3390/nano7020048

8. DelaFuente-Nunez, C., Torres, M.D., Mojica, F.J. and Lu, T.K. (2017) Next Generation Precision Antimicrobials: Towards Personalized Treatment of Infectious Diseases. Current Opinion in Microbiology, 37, 95-102. https://doi.org/10.1016/j.mib.2017.05.014

9. Muñoz-Bonilla, A., Echeverria, C., Sonseca, Á., Arrieta, M.P. and Fernández-García, M. (2019) Bio-Based Polymers with Antimicrobial Properties towards Sustainable Development. Materials, 12, 641. https://doi.org/10.3390/ma12040641

10. Raafat, D., Von Bargen, K., Haas, A. and Sahl, H.-G. (2008) Insights into the Mode of Action of Chitosan as An. Applied and Environmental Microbiology, 74, 3764-3773. https://doi.org/10.1128/AEM.00453-08

11. Soliman, E.A., El-Moghazy, A.Y., El-Din, M.S.M. and Massoud, M.A. (2013) Microencapsulation of Essential Oils within Alginate: Formulation and in Vitro Evaluation of Antifungal Activity. Journal of Encapsulation and Adsorption Sciences, 3, 48-55. https://doi.org/10.4236/jeas.2013.31006

12. Turasan, H., Sahin, S. and Sumnu, G. (2015) Encapsulation of Rosemary Essential Oil. LWT-Food Science and Technology, 64, 112-119. https://doi.org/10.1016/j.lwt.2015.05.036

13. Martins, I.M.D. (2012) Microencapsulation of Thyme Oil by Coacervation: Production, Characterization and Release Evaluation. 4-90.

14. Theisinger, S., Schoeller, K., Osborn, B., Sarkar, M. and Landfester, K. (2009) Encapsulation of a Fragrance via Miniemulsion Polymerization for Temperature-Controlled Release. Macromolecular Chemistry and Physics, 210, 411-420. https://doi.org/10.1002/macp.200800499

15. Madene, A., Jacquot, M., Scher, J. and Desobry, S. (2006) Flavour Encapsulation and Controlled Release: A Review. International Journal of Food Science and Technology, 41, 1-21. https://doi.org/10.1111/j.1365-2621.2005.00980.x

16. Vergis, J., Gokulakrishnan, P., Agarwal, R.K. and Kumar, A. (2015) Essential Oils as Natural Food Antimicrobial Agents: A Review. Critical Reviews in Food Science and Nutrition, 55, 1320-1323. https://doi.org/10.1080/10408398.2012.692127

17. Butstraen, C. and Salaün, F. (2014) Preparation of Microcapsules by Complex Coacervation of Gum Arabic and Chitosan. Carbohydrate Polymers, 99, 608. https://doi.org/10.1016/j.carbpol.2013.09.006

18. Xiao, Z., Liu, W., Zhu, G., Zhou, R. and Niu, Y. (2014) Production and Characterization of Multinuclear Microcapsules Encapsulating Lavender Oil by Complex Coacervation. Flavour and Fragrance Journal, 29, 166. https://doi.org/10.1002/ffj.3192

19. Yang, Z., Peng, Z., Li, J., Li, S., Kong, L., Li, P. and Wang, Q. (2014) Development and Evaluation of Novel Flavour Microcapsules Containing Vanilla Oil Using Complex Coacervation Approach. Food Chemistry, 145, 272. https://doi.org/10.1016/j.foodchem.2013.08.074 
20. Sharkawy, A., Fernandes, P., Barreiro, M., Rodrigues, E. and Shoeib, T. (2017) Aroma-Loaded Microcapsules with Antibacterial Activity for Ecofriendly Textile Application: Synthesis, Characterization, Release and Green Grafting. Industrial \& Engineering Chemistry Research, 56, 5516-5526. https://doi.org/10.1021/acs.iecr.7b00741

21. AATCC American Association of Textile Chemists and Colorists (2015) AATCC-Technical Manual. AATCC, 90, 512.

22. AATCC Test Method (2010) Antibacterial Finishes on Textile Materials: Assessment of AATC Technical Manual, 1988. 142-144.

23. Cavalieri, S.J., et al. (2005) Manual de Pruebas de Susceptibilidad Antimicrobiana.

24. Yang, Z., Zeng, Z., Xiao, Z. and Ji, H. (2014) Preparation and Controllable Release of Chitosan/Vanillin Microcapsules and Their Application to Cotton Fabric. Flavour and Fragrance Journal, 29, 114. https://doi.org/10.1002/ffj.3186

25. Fan, F., Zhang, W. and Wang, C. (2015) Covalent Bonding and Photochromic Properties of Double-Shell Polyurethane-Chitosan Microcapsules Crosslinked onto Cotton Fabric. Cellulose, 22, 1427. https://doi.org/10.1007/s10570-015-0567-5

26. Pantoja-Castro, M.A. and González-Rodríguez, H. (2012) Study by Infrared Spectroscopy and Thermogravimetric Analysis of Tannins and Tannic Acid. Revista Latinoamericana de Química, 39, 107-112. http://www.scielo.org.mx/scielo.php?script=sci_arttext\&pid=S0370-59432011000200003\&lng=es\&nrm=iso\&tln $\mathrm{g}=\mathrm{en}$ 